\title{
Effect of Age on Myocardial Adaptation to Volume Overload in the Rat
}

Shogen Isoyama, William Grossman, and Jeanne Y. Wei

The Charles A. Dana Research Institute, Boston, Massachusetts 02215;

Harvard-Thorndike Laboratory and Department of Medicine, Cardiovascular and Gerontology Divisions, Beth Israel Hospital, Boston, Massachusetts 02215, and Harvard Medical School, Boston, Massachusetts 02215

\section{Abstract}

To test the hypothesis that the capacity for left ventricular (LV) adaptation to volume overload might diminish with age, we examined the hemodynamics and degree of myocardial hypertrophy in response to aortic insufficiency in young adult ( 9 mo) and old (18 or 22 mo) Fischer rats. Before, immediately after, and at 2 and 4 wk after creating aortic insufficiency, LV and aortic pressures were measured using a catheterization technique. 4 wk after surgery, we measured aortic flow, and estimated the $L V$ passive pressure-volume relationship and the degree of $\mathrm{LV}$ hypertrophy after killing. Immediately after the surgical creation of aortic insufficiency, both young and old rats showed similar elevation of $\mathrm{LV}$ end-diastolic pressure (from $4.8 \pm 0.6$ to $12.0 \pm 1.5 \mathrm{mmHg}$ in the young rats, $P<0.01$; from $4.9 \pm 0.4$ to $11.0 \pm 0.7 \mathrm{mmHg}$ in the old rats, $P<0.01$ ). In the young rats $L V$, end-diastolic pressure decreased to 8.0 \pm 1.0 and to $8.5 \pm 0.9 \mathrm{mmHg}$ at 2 and 4 wk $(P<0.05)$. In contrast, LV end-diastolic pressure at $2(16.9 \pm 3.1 \mathrm{mmHg})$ and $4 \mathrm{wk}$ $(16.1 \pm 2.7 \mathrm{mmHg}$ ) in the old rats was even higher, compared with the values measured immediately after aortic insufficiency. At 4 wk, LV end-diastolic meridional wall stress (calculated from the in vivo LV end-diastolic pressure, and the pressure-volume relationship and muscle mass obtained after killing) was higher in the old rats than in the young rats. In the young rats, the diastolic pressure-volume relationship at $4 \mathrm{wk}$ shifted to the right $(P<0.01)$, and $L V$ dry weight, LV dry weight/tibial length, and protein content of the $L V$ myocardium increased by 26\% $(P<0.01), 24 \%(P<0.01)$, and 33\% $(P$ $<0.01$ ), respectively. However, old rats with aortic insufficiency did not show a significant change in the pressure-volume relationship, dry weight, or protein content at 4 wk. These results suggest that advanced age diminishes the capacity for LV hypertrophy in response to a volume overload, and this reduced $\mathrm{LV}$ hypertrophic response in the old rats resulted in persistent elevation of $\mathrm{LV}$ end-diastolic pressure and wall stress.

\section{Introduction}

It is well known that heart failure occurs more frequently in old patients compared with younger individuals when subjected to similar stress (1). Increased circulatory demand

Address correspondence to Dr. Wei, Beth Israel Hospital, 330 Brookline Ave., Boston, MA 02215.

Received for publication 25 June 1987 and in revised form $18 \mathrm{De}$ cember 1987.

J. Clin. Invest.

(C) The American Society for Clinical Investigation, Inc.

0021-9738/88/06/1850/08 $\$ 2.00$

Volume 81, June 1988, 1850-1857 causes cardiac hypertrophy as part of the process of physiologic adaptation $(2,3)$. The higher incidence of heart failure in old patients might be associated with a diminished capacity for hypertrophy in response to a given stress $(4,5)$. Effects of age on cardiac hypertrophic response may depend upon the type of stimulus. In the reports of Florini et al. (6) and Zitnik and Roth (7), there was no significant difference in the extent of hypertrophy between young adult and old animals when the cardiac hypertrophy was induced by thyroid hormone administration. On the other hand, in the report of McCafferty and Edington (8) the extent of cardiac hypertrophy induced by exercise was less in the senescent compared to young adult animals. In addition, in a previous study (9) we reported that the cardiac hyprtorphy induced by left ventricular (LV) ${ }^{1}$ pressure overload was substantially less in old compared with young adult rats.

It has been suggested that increased hemodynamic load, i.e., pressure overloading or volume overloading, induces different patterns of hypertrophy through different processes of adaptation; concentric hypertrophy in response to pressure overload and eccentric hypertrophy in response to volume overload $(2,4,5,10,11)$. Additionally, aging per se results in a modest increase in heart weights and in the size of individual myocytes in humans and animals $(8,12-17)$. This age-associated change is functionally similar to that produced by pressure overload $(12,14)$. Therefore, the effect of volume overload superimposed on the sensecent heart is not established. The myocardial response may depend upon the type of increased hemodynamic load and may be different for pressure overload compared with volume overload.

To test the hypothesis that advanced age may diminish the capacity for cardiac hypertrophy in response to a stimulus of volume overload, and to examine whether the degree of hypertrophy may correlate with the hemodynamic load, we created aortic insufficiency (AI) and studied the hemodynamics and the degree of hypertrophy in young adult and old rats.

\section{Methods}

Two age groups of male Fischer 344 rats were obtained from Harlan Sprague-Dawley, Inc. (Indianapolis, IN): young adult rats of 9 mo of age $(n=30)$, and aged rats of 18 or $22 \mathrm{mo}$ of age $(n=37)$. Before the operation all rats were housed for at least $3 \mathrm{~d}$ in the Animal Quarters of the Harvard-Thorndike Laboratory, at $23^{\circ} \pm 1^{\circ} \mathrm{C}$ on a 12 -h light/dark cycle and were fed rat chow (Ralston-Purina Co., St. Louis, MO) and tap water ad lib.

Operative procedure for AI and hemodynamic measurements. Each rat was anesthetized with pentobarbital sodium $(40 \mathrm{mg} / \mathrm{kg}$ i.p.). To ensure uniform timing of the LV end-diastolic point, we recorded the

1. Abbreviations used in this paper: AI, aortic insufficiency; LV, left ventricular; $\mathbf{R V}$, right ventricular. 
electrocardiogram (ECG) using standard limb leads. As in the previous reports $(9,18)$, a polyethylene cannula (Intramedic polyethylene tubing [PE-10]: 0.28 and $0.61 \mathrm{~mm}$ o.d.; Becton-Dickinson \& Co., Mountain View, CA) was inserted into the right carotid artery and aortic pressure was monitored using a Statham P23 physiologic transducer. To measure $L V$ pressure, the cannula was advanced into the LV. After removing the cannula, a stiffer and wider cannula (PE-50, $0.58 \mathrm{~mm}$ i.d., $0.965 \mathrm{~mm}$ o.d.) containing a stainless steel wire was again inserted into the right carotid artery and was pushed toward the aortic valve to create AI by mechanical interruption $(19,20)$. After AI was created, $\mathrm{LV}$ and aortic pressures were again measured using the PE- 10 cannula as described above. Zero level for pressure measurement was taken to be at the mid-chest level.

After repeat measurements were made, the right carotid artery was ligated, and the skin incisions were sutured. Postoperatively, the rats were maintained on standard rat chow and water ad lib. for the ensuing $4 \mathrm{wk}$. In the age-matched control rats, surgical dissection and measurements were performed as described without creation of AI; postoperative care was the same as that for the AI group.

In pilot studies, the PE-50 cannula (even without the stainless steel wire) occasionally caused $\mathrm{AI}$ and changed aortic pulse pressure after the cannula was advanced into the LV to measure LV pressure. Therefore, in this study, the PE-50 cannula was used for creation of AI and the PE-10 for measurements.

At 2 wk after the operation, each rat with $\mathrm{AI}$ was again anesthetized. The cannula (PE-10) was introduced from the proximal portion of the right carotid artery, and pressure measurements were performed as described above.

At 4 wk after the operation, the PE-10 cannula was introduced from the left carotid artery under anesthesia, and aortic and LV pressures were measured in both the age-matched control and AI rats as described above. Endotracheal intubation was performed with direct visualization. Under controlled ventilation (rodent ventilator, model 683, Harvard Apparatus Co., Inc., South Natick, MA) with room air, the thorax was opened at the third intercostal space to expose the ascending aorta. An electromagnetic flow probe $(2.5 \mathrm{~mm}$ in diameter, BL 6025-H55, Biotronex Laboratory, Kensington, MD) was positioned around the ascending aorta to measure aortic flow. Zero level of aortic flow was obtained by momentary occlusion of the aorta using a snare positioned just distal to the flow probe. Regurgitant fraction and total and forward LV stroke volumes were determined from the aortic flow measurement. After these measurements, the flow probe was removed and the arterial catheter advanced into the LV. The ascending aorta was occluded briefly around the catheter by the snare to produce contractions that were isovolumic except for coronary flow. Measurements were made of LV peak systolic, end-diastolic, and developed pressures from the first stable six or seven beats (21).

After "in vivo" measurements were made, the passive LV pressure-volume relationship was defined. A solution containing $3 \mathrm{~mol}$ $\mathrm{KCl}$ was infused into the jugular vein, and the heart, arrested in diastole, was removed rapidly and submerged in cold saline $\left(4^{\circ} \mathrm{C}\right)(22)$. A double-lumen catheter was introduced into the LV through the aorta and was ligated just below the stems of the left and right coronary arteries. The atrioventricular groove was also ligated with a suture. The right ventricular (RV) free wall was cut to negate the effect of RV distension on the LV pressure-volume relationship $(22,23)$. Before infusion of cold saline the $\mathrm{LV}$ was emptied by $-10 \mathrm{mmHg}$ and by manual compression. The pressure-volume relationship was obtained with stepwise increments of $0.05 \mathrm{ml}$ of saline at intervals of $15 \mathrm{~s}$ up to $40 \mathrm{mmHg}$ of $\mathrm{LV}$ pressure. This procedure was repeated three times within 15 min of cardiac arrest in the cold saline and showed that the pressure-volume relationship was reproducible.

Frequency response of our pressure measurement system indicated that the damping coefficient was $\mathbf{0 . 8 6}$ and the undamped natural frequency was $49 \mathrm{~Hz}$ (24). A pulse change of pressure was measured with a high fidelity pressure micromanometer catheter system and our pressure measurement system simultaneously. The time delay between the signals obtained by these systems was $15 \mathrm{~ms}$. Therefore, the time delay in our pressure measurement system was taken into account when the hemodynamic measurements were made relative to the timing of the ECG recordings. Frequency response of the flow measurement system was 3 decibels down at $100 \mathrm{~Hz}$.

Estimation of the degree of hypertrophy in the left and right ventricles. Body weights were measured before (initial body weight) and at 4 wk after surgical creation of AI or sham operation (final body weight). The heart was stripped of fat and appendages, and divided into an RV free wall portion and an LV-septal portion. After measurements of LV and $R V$ wet weights were made, the $L V$ was cut into two portions. The one portion involving the ventricular septum was reweighed, and dried to constant weight at $70^{\circ} \mathrm{C}(72 \mathrm{~h})$. The dry/wet weight ratio of the portion was obtained, and total LV dry weight was calculated from the total LV wet weight and the dry/wet weight ratio of the portion. To normalize the heart weight to body size, one leg was removed above the knee joint, and the length of the tibia was measured $(15,17)$. Degree of hypertrophy in the LV or RV was expressed as the ratio of dry ventricular weight/tibial length, to avoid any potential confound by age or AI on the final body weight. The other portion was saved in liquid nitrogen and myocardial tissue protein was measured by the method of Lowry (25). Wet and dry weights of lung and liver tissues were also measured.

Calculation of wall stress. In calculating LV wall stress, we made the following assumptions: (a) the shape of the LV cavity is spherical; (b) LV wall thickness is uniform at all portions of the $\mathrm{LV}$; (c) specific gravity of the myocardial tissue is $1.06(26)$; and $(d)$ LV muscle is not compressible. Meridional stress of the LV wall $(\sigma)$ was then calculated using the following equations $(2,27)$ :

$$
\begin{aligned}
V m & =W m / 1.06 \\
R i & =\sqrt[3]{3 V_{i} / 4 \pi} \\
R o & =\sqrt[3]{3\left(V_{i} \pm V_{m}\right) / 4 \pi} \\
h & =R o-R i \\
\sigma & =P R i / 2 h(1+h / 2 R i),
\end{aligned}
$$

where $\mathrm{Vm}$ is volume of the $\mathrm{LV}$ muscle; $\mathrm{Wm}$ is directly measured wet weight of the $\mathrm{LV}$ muscle; $\mathrm{Ri}$ is internal diameter of the $\mathrm{LV}$ cavity; $\mathrm{Vi}$ is $L V$ cavity volume that was obtained from the passive pressure-volume relationships directly measured after killing and the LV pressure measured during life; Ro is outer diameter of the LV; $h$ is wall thickness; and $P$ is $L V$ pressure measured during life.

Statistical analysis. Variables measured are expressed as mean \pm standard error. The statistical significance of differences in mean values between the age-matched control and AI rats, and between the young and old rats with or without AI, were assessed by the unpaired Student's $t$ test. The Bonferroni correction was applied for multiple comparisons to reduce the possibility of chance significance.

\section{Results}

Operative mortality and body weight. General mortality was higher in the old rats $(57 \%)$ than in the young adult rats $(37 \%)$. It was higher in the rats with $\mathrm{AI}(56 \%)$ than in the age-matched control rats (35\%). Rats dying within 1 wk after the first operation comprised $81 \%$ of all the postoperative mortality during the 4-wk period.

As summarized in Table $I$, there was no difference in initial body weight or tibial length between the control and AI rats within each age group. As expected, initial body weight and tibial length were greater in the old rats than in the young adult rats. Control rats of both age groups gained slightly in weight over the 4-wk period; the old rats with AI lost weight $(P$ $<0.05$ ). Final body weight of rats with AI was lower in both the young adult and old groups, compared with their respective age-matched controls $(P<0.05)$. 
Table I. Body Weight, Tibial Length, and Ventricular Weights in Young and Old Rats

\begin{tabular}{|c|c|c|c|c|}
\hline & \multicolumn{2}{|c|}{ Young rats } & \multicolumn{2}{|c|}{ Old rats } \\
\hline . & $\begin{array}{c}\text { Control } \\
(n=9)\end{array}$ & $\mathrm{AI}(n=10)$ & $\begin{array}{l}\text { Control } \\
(n=8)\end{array}$ & $\mathrm{AI}(n=8)$ \\
\hline Initial body weight $(g)$ & $375 \pm 8$ & $365 \pm 9$ & $406 \pm 15^{8}$ & $406 \pm 9$ \\
\hline Final body weight $(g)$ & $387 \pm 6$ & $360 \pm 8^{*}$ & $416 \pm 15^{6}$ & $367 \pm 12^{*}$ \\
\hline Tibial length $(\mathrm{cm})$ & $4.38 \pm 0.03$ & $4.42 \pm 0.01$ & $4.54 \pm 0.03^{8}$ & $4.52 \pm 0.04^{8}$ \\
\hline LV wet weight $(m g)$ & $712 \pm 19$ & $940 \pm 28^{\ddagger}$ & $828 \pm 21^{8}$ & $898 \pm 30$ \\
\hline LV dry weight $(m g)$ & $154 \pm 5$ & $194 \pm 6^{\ddagger}$ & $183 \pm 3^{3}$ & $188 \pm 7$ \\
\hline RV wet weight $(m g)$ & $160 \pm 6$ & $208 \pm 10^{\ddagger}$ & $163 \pm 4$ & $219 \pm 13^{\ddagger}$ \\
\hline RV dry weight $(m g)$ & $32 \pm 1$ & $41 \pm 2^{\ddagger}$ & $35 \pm 2$ & $46 \pm 4^{\ddagger}$ \\
\hline
\end{tabular}

Values are mean $\pm \mathrm{SE}$.

* $P<0.05,{ }^{\ddagger} P<0.01$, statistical significance of differences between the mean values in the rats with and without $A I$ in each age group.

${ }^{8} P<0.01$, statistical significance of differences between the mean values in the young and old rats in the age-matched control or AI rats.

Hemodynamics. Fig. 1 shows representative tracings of LV and aortic pressures, and ECG recorded in young adult and old rats before, immediately after, and at 4 wk after creation of AI. In both the young adult and the old rat, aortic pulse pressure increased immediately after induction of AI, and did not change in the next $4 \mathrm{wk}$. The LV end-diastolic pressure increased from 4 to $11 \mathrm{mmHg}$ in the young adult rat and from 4 to $9 \mathrm{mmHg}$ in the old rat immediately after induction of AI. In the young adult rat, $\mathrm{LV}$ end-diastolic pressure decreased from 11 to $7 \mathrm{mmHg}$ at 4 wk after $\mathrm{AI}$; in contrast, in the old rat, LV end-diastolic pressure actually increased from 9 to $22 \mathrm{mmHg}$ at 4 wk after AI. Regurgitant fraction obtained from the aortic flow tracings at 4 wk after AI was similar in the young adult and the old rat seen in Fig. 1.

Before AI, there was no difference in aortic systolic, diastolic, or pulse pressures between the young adult and old rats or between the control and AI rats as seen in Fig. 2. Immediately after AI, aortic systolic pressure decreased slightly; diastolic pressure decreased significantly in both the young adult and old rats $(P<0.01$ and $P<0.05$, respectively). Pulse pressure increased from $29 \pm 2$ to $42 \pm 2 \mathrm{mmHg}(P<0.01)$ in the young rats and from $26 \pm 1$ to $38 \pm 2 \mathrm{mmHg}(P<0.01)$ in the old rats. Pulse pressure in the AI rats was greater than that in the age-matched control rats at 4 wk in both the young adult and old rats $(P<0.01)$.

As seen in Fig. 3, LV end-diastolic pressure increased from $4.8 \pm 0.6$ to $12.0 \pm 1.5 \mathrm{mmHg}$ in the young adult rats $(P<0.01)$ and from $4.9 \pm 0.4$ to $11.0 \pm 0.7 \mathrm{mmHg}$ in the old rats $(P<0.01)$ immediately after induction of AI. The LV end-diastolic pressure in the young adult rats decreased from $12.0 \pm 1.5$ to $8.0 \pm 1.0 \mathrm{mmHg}$ at $2 \mathrm{wk}(P<0.05)$ and did not change thereafter. The value at $4 \mathrm{wk}(8.5 \pm 0.9 \mathrm{mmHg})$ was still higher compared with the value before $\mathrm{AI}(P<0.05)$ or the value at $4 \mathrm{wk}$ in the age-matched controls $(P<0.05)$. In contrast, in the old rats the $\mathrm{LV}$ end-diastolic pressure at $2 \mathrm{wk}$ increased to $16.9 \pm 3.1 \mathrm{mmHg}$, and the value was higher than that in the young adult rats $(P<0.01)$. This high $\mathrm{LV}$ end-diastolic pressure in the old rats did not decrease even at 4 wk after AI.

Fig. 4 shows the passive LV pressure-volume relationship obtained after killing ( $\mathrm{KCl}$ arrest) in the young adult and old rats. The relationship in the old control rats positioned at the right of that of the young adult rats because the heart size was bigger by $16 \%(P<0.01)$ in wet weight in the old rats than in the young adult rats (Table I). The relationship shifted to the right in the young adult rats after 4 wk of $\mathrm{AI}(P<0.01)$. In contrast, the relationship in the old rats did not shift significantly after 4 wk of AI.

LV end-diastolic volume during life was estimated from the passive pressure-volume relationship (Fig. 4) and end-diastolic pressure measured before killing. As seen in Table II, LV end-diastolic volume was greater with age and in the young rats with AI compared with their age-matched controls. The ratio of $\mathrm{LV}$ wall thickness/internal radius at end-diastole was smaller after induction of AI in both age groups, and the control rats did not show a significant difference between the two age groups. LV total stroke volume was greater after induction of $\mathrm{AI}$ in both the young adult and old rats, and there was no significant difference in regurgitant fraction between the young adult and old rats with $\mathrm{AI}$.

As seen in Fig. 5, in both the young adult and old rats, LV end-diastolic wall stress was higher in the AI rats than in the age-matched controls $(P<0.01$ and $P<0.01$, respectively). In the old rats with $\mathrm{AI}$, the $\mathrm{LV}$ end-diastolic stress was higher compared with the young adult rats with AI $(P<0.01)$. LV peak systolic stress tended to be higher after 4 wk of $A I$ in each age group, but this difference was not statistically significant.

LV isovolumic systolic and developed pressures did not differ between the young adult and old rats, and were lower in the rats with $\mathrm{AI}$ in each age group $(P<0.01)$, as seen in Fig. 6 . Peak isovolumic systolic wall stress was slightly lower in the old rats than in the young adult rats; there was no significant difference in peak isovolumic systolic wall stress between the rats with and without $\mathrm{AI}$. The maximum LV developed wall stress during isovolumic contraction was lower in the old rats with AI, compared with the age-matched controls or the young adult rats with $\mathrm{AI}(P<0.01)$.

Heart weight and protein content. Dry weight in the LV increased by $19 \%$ with age $(P<0.01)$, but did not change in the $\mathrm{RV}$ as summarized in Table I. In the young adult rats, LV dry weight increased by $26 \pm 4 \%$ after 4 wk of $\mathrm{AI}$, compared with the age-matched controls $(P<0.01)$. In contrast, the old rats did not show a significant increase in the LV dry weight after 4 wk of $\mathrm{AI}(2 \pm 4 \%, \mathrm{NS})$. On the other hand, RV dry weight increased by $28 \pm 6 \%(P<0.01)$ and by $32 \pm 10 \%(P<0.01)$ in the young adult and old rats, respectively. As shown in Fig. 7, the ratio of dry weight/tibial length increased by $14 \%$ in the LV with age, but did not increase in the RV. The ratio of LV dry weight/tibial length increased by $24 \pm 3 \%(P<0.01)$ in the young adult rats after 4 wk of $\mathrm{AI}$, compared with the agematched controls $(P<0.01)$. In contrast, the old rats with $\mathrm{AI}$ did not show a significant increase in the ratio $(2 \pm 4 \%)$. Of interest, 4 wk after induction of $\mathrm{AI}$ both the young adult and old rats showed significant RV hypertrophy $(27 \pm 6 \%, P<0.01$, and $32 \pm 10 \%, P<0.01$, above their controls, respectively); there was no significant difference between the young adult and old rats.

As summarized in Table III, protein content in the LV myocardium of the young adult rats was greater by $33 \%$ after 4 wk of AI than that in the age-matched controls $(P<0.01)$; however, the old rats with AI showed only a slight increase in protein content compared with the age-matched controls.

Water content of the lung was significantly higher in the old rats after 4 wk of AI compared with the age-matched control rats $(78.3 \pm 1.3$ vs. $75.3 \pm 1.2 \%, P<0.05)$, but there was no 
A

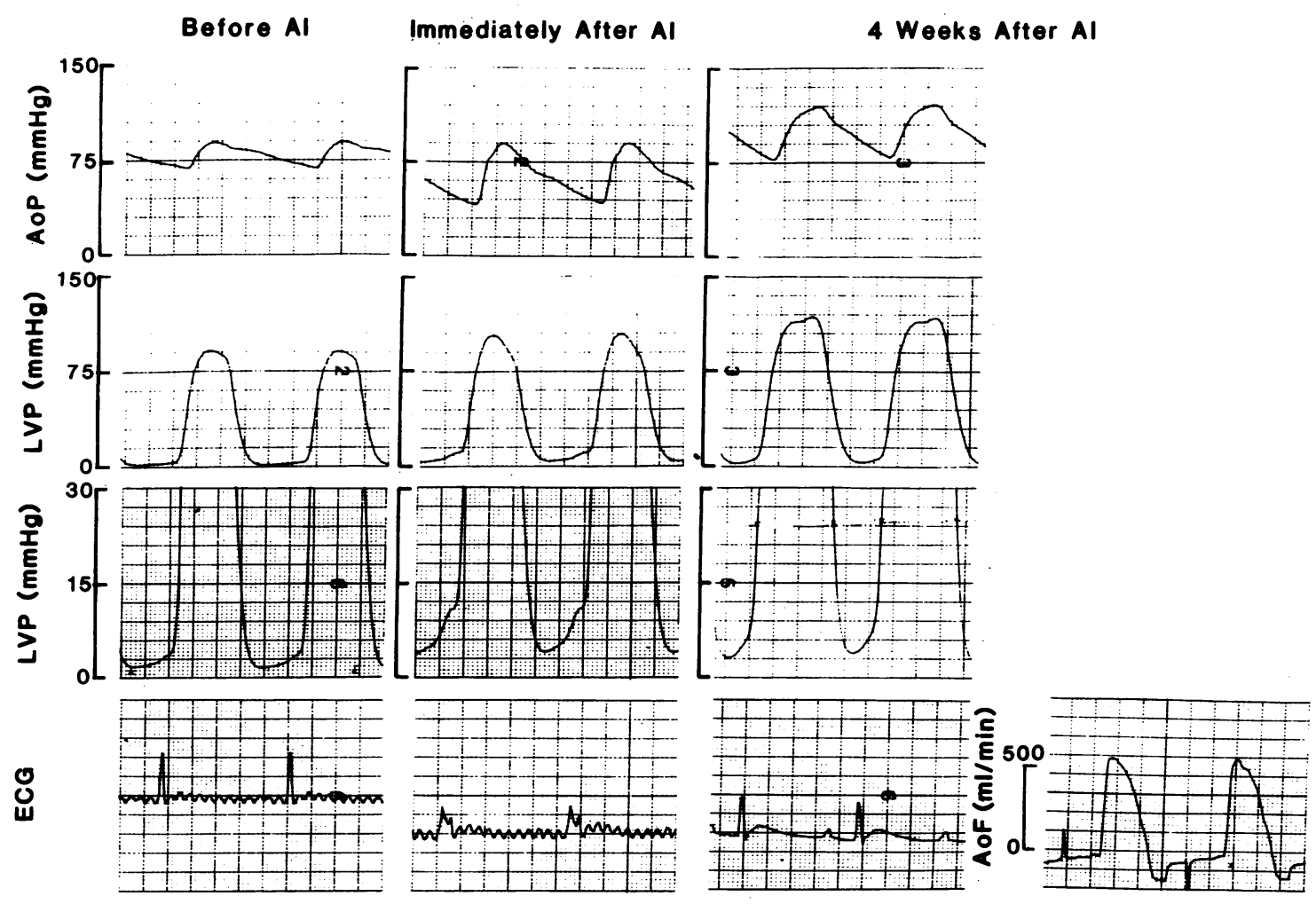

B

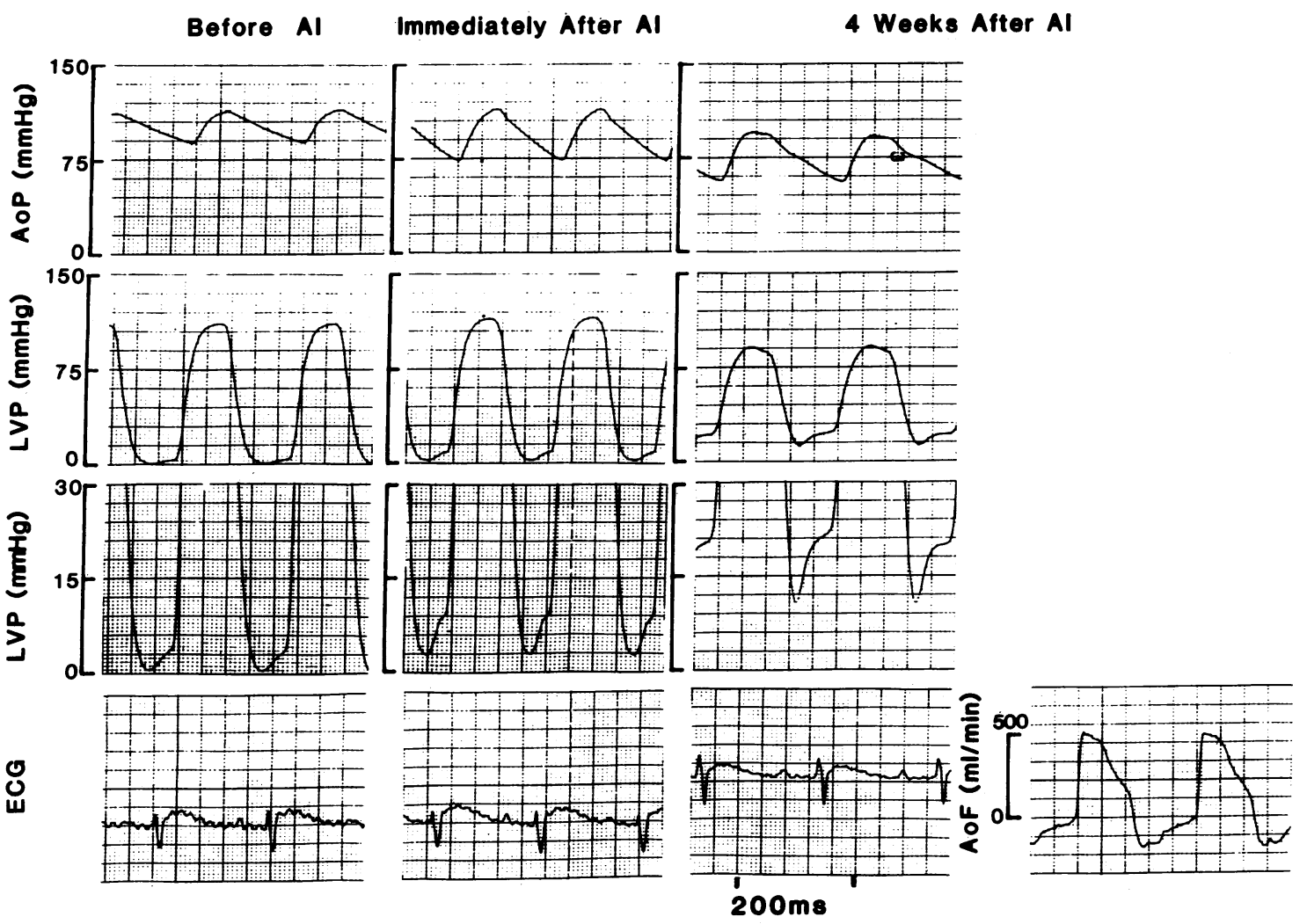

Figure 1. Representative tracings of aortic (AoP) and LV pressures, ECG, and aortic flow (AoF), measured before, immediately after, and at 4 wk after induction of $\mathrm{AI}$ in young $(A)$ and old rats $(B)$. See text for details. 

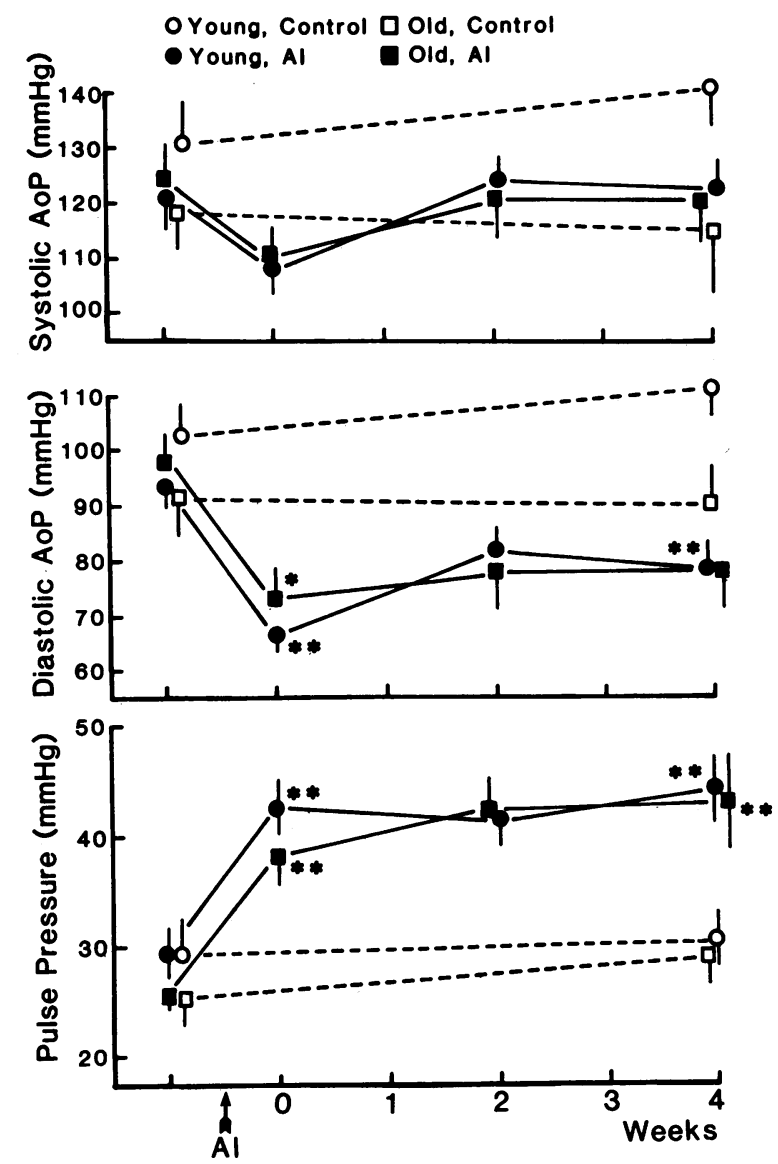

Figure 2. Changes in aortic pressure (AoP) in young and old rats with or without AI. Values are mean \pm SE. ${ }^{*} P<0.05,{ }^{* *} P<0.01$, statistical significance of differences between the mean values in the rats with and without $\mathrm{AI}$ in each age group.

significant difference between the young adult rats with and without $\mathrm{AI}(76.1 \pm 0.9$ vs. $74.7 \pm 1.2 \%)$. In water content of the liver, there was no difference between young adult and old rats, or between the rats with and without AI within each age group.

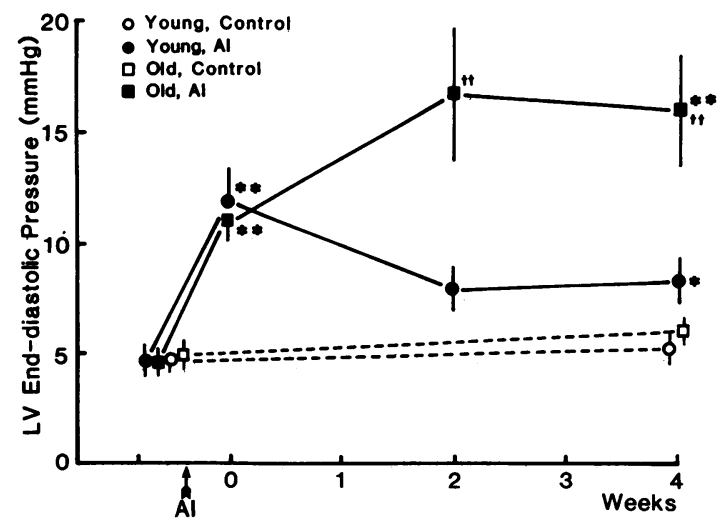

Figure 3. Changes in LV end-diastolic pressure in young and old rats before, immediately after, and at 2 and $4 \mathrm{wk}$ after induction of $\mathrm{AI}$. Values are mean $\pm \mathrm{SE} .++P<0.01$, statistical significance of differences between the mean values in the young and old rats in the agematched control or AI rats. Other symbols are the same as in Fig. 2.

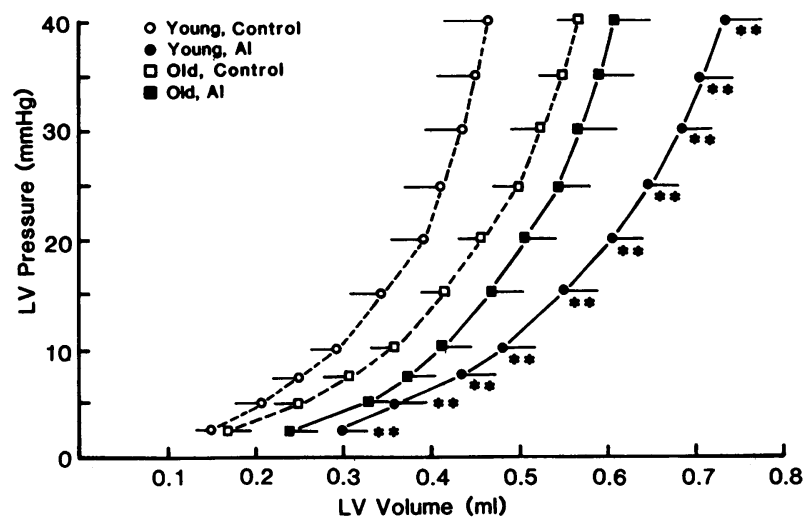

Figure 4. LV passive pressure-volume relationships obtained at 4 wk after induction of $\mathrm{AI}$ in young and old rats with or without $\mathrm{AI}$. Values are mean \pm SE. Symbols are the same as in Fig. 2.

\section{Discussion}

In this study, age-related differences in hypertrophic response and hemodynamics were examined under the same degree of stimulation of volume overload to the $\mathrm{LV}$ in young adult and old rats. There was no significant age difference in the LV end-diastolic pressure, aortic diastolic, and pulse pressures that were measured immediately after induction of AI (Figs. 2 and 3 ), or in the aortic regurgitant fraction measured 4 wk later (Table II). In our experimental model, systolic wall stress was slightly higher in the AI rats than in the age-matched control rats at 4 wk after induction of $\mathrm{AI}$ (Fig. 5). However, there was no significant difference between the young adult and old rats with AI. Although we did not directly measure the LV systolic and end-diastolic wall stress immediately after induction of AI, it is reasonable to assume that the difference in severity of

Table II. Changes in Heart Rate, LV Chamber Volume, and Regurgitant Fraction at 4 wk after Induction of $A I$ in Young Adult and Old Rats

\begin{tabular}{|c|c|c|c|c|}
\hline & \multicolumn{2}{|c|}{ Young rats } & \multicolumn{2}{|c|}{ Old rats } \\
\hline & Control $(n=9)$ & $\mathrm{AI}(n=10)$ & Control $(n=8)$ & $\mathrm{AI}(n=7)$ \\
\hline $\begin{array}{c}\text { HR (beats } \\
\text { minute) }\end{array}$ & $377 \pm 14$ & $355 \pm 21$ & $327 \pm 19^{8}$ & $331 \pm 9$ \\
\hline $\operatorname{EDV}(m l)$ & $0.21 \pm 0.03$ & $0.47 \pm 0.03^{*}$ & $0.28 \pm 0.03$ & $0.47 \pm 0.05^{*}$ \\
\hline $\mathbf{h} / \mathbf{R i}$ & $0.67 \pm 0.06$ & $0.43 \pm 0.02^{*}$ & $0.60 \pm 0.05$ & $0.43 \pm 0.06^{\ddagger}$ \\
\hline $\operatorname{TSV}(m l)$ & $0.17 \pm 0.01$ & $0.39 \pm 0.03^{*}$ & $0.24 \pm 0.02^{8}$ & $0.41 \pm 0.06^{*}$ \\
\hline $\begin{array}{l}\mathrm{SV}_{\text {forward }} \\
(\mathrm{ml})\end{array}$ & $0.17 \pm 0.01$ & $0.29 \pm 0.03^{*}$ & $0.24 \pm 0.02^{8}$ & $0.30 \pm 0.05$ \\
\hline RF & 0 & $0.25 \pm 0.03$ & 0 & $0.29 \pm 0.03$ \\
\hline
\end{tabular}

Values are mean $\pm S E$. Abbreviations: $H R$, Heart rate; $h / R i$, ratio of LV wall thickness to internal radius at end-diastole; EDV, LV enddiastolic volume; TSV, LV total stroke volume; $\mathrm{SV}_{\text {forward }}, \mathrm{LV}$ forward stroke volume; $R F$, regurgitant fraction.

${ }^{*} P<0.01,{ }^{\ddagger} P<0.05$, statistical significance of differences between the mean values in the rats with and without $\mathrm{AI}$ in each age group. ${ }^{8} P<0.05$, statistical significance of differences between the mean values in the young and old rats in the age-matched control or AI rats. 

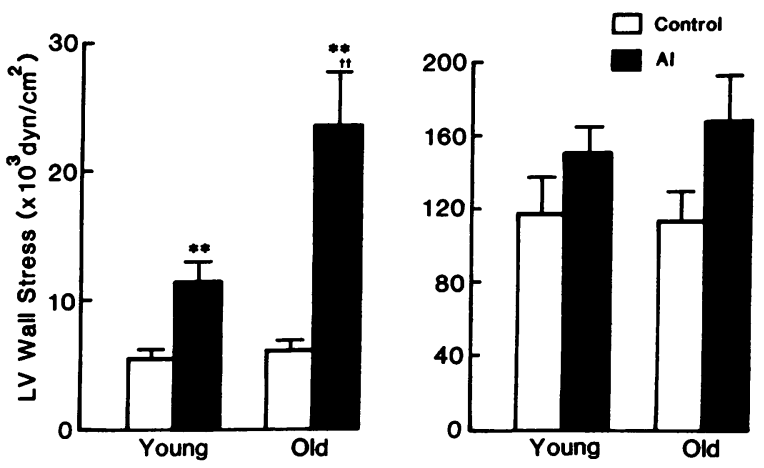

Figure 5. LV end-diastolic (left) and peak systolic (right) wall stress in young and old rats with or without AI. Values are mean \pm SE. Symbols are the same as in Figs. 2 and 3.

hemodynamic stimulus between young adult and old rats was minimal in the initial period of the experiment. In the control rats, the ratio of $\mathrm{LV}$ wall thickness to internal radius, which was measured at the end of the experiment, should be similar to the ratio at the beginning of the experiment for the following reasons. First, the control young adult and old rats did not show a significant difference in the ratio measured at the end of the experiment (Table II). Second, the 4-wk experimental period is not long enough to result in any age-related changes
LV Syst and Diast $P(\mathbf{m m H g})$

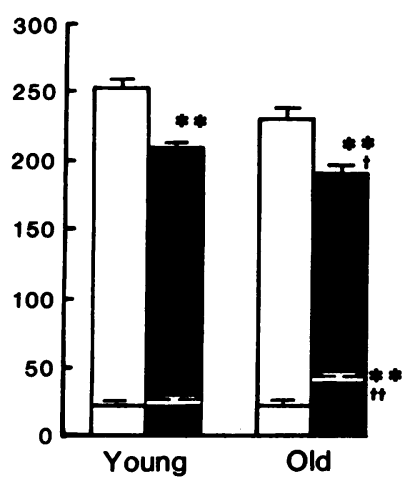

LV Syst and Diast Wall Stress $\left(\times 10^{3} \mathrm{dyn} / \mathrm{cm}^{2}\right)$

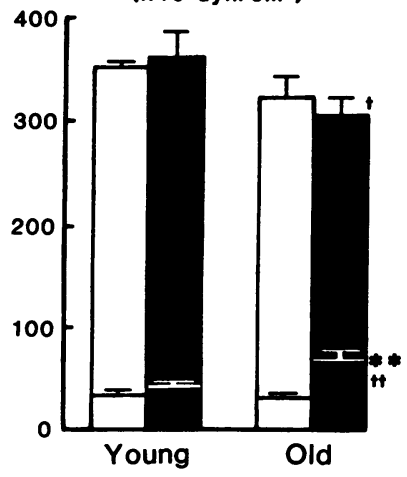

LV Developed $P(\mathbf{m m H g})$

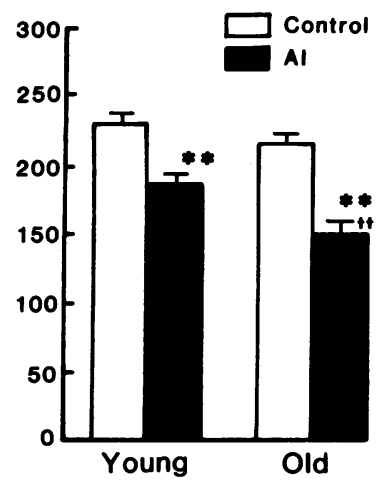

LV Developed Wall Stress $\left(x 10^{3} \mathrm{dyn} / \mathrm{cm}^{2}\right)$

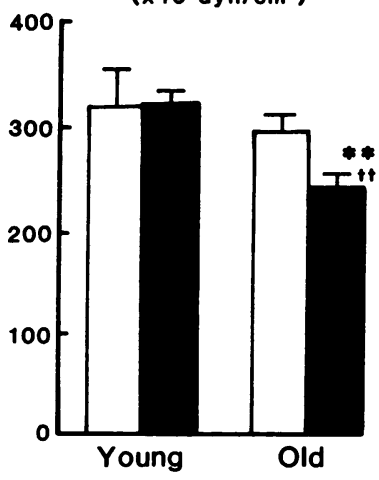

Figure 6. Isovolumic $\mathrm{LV}$ pressure and wall stress at $4 \mathrm{wk}$ after induction of AI in young and old rats with or without AI. Values are mean \pm SE. $\dagger P<0.05$, statistical significance of differences between the mean values in the young and old rats in the age-matched control or AI rats. Other symbols are the same as in Figs. 2 and 3.
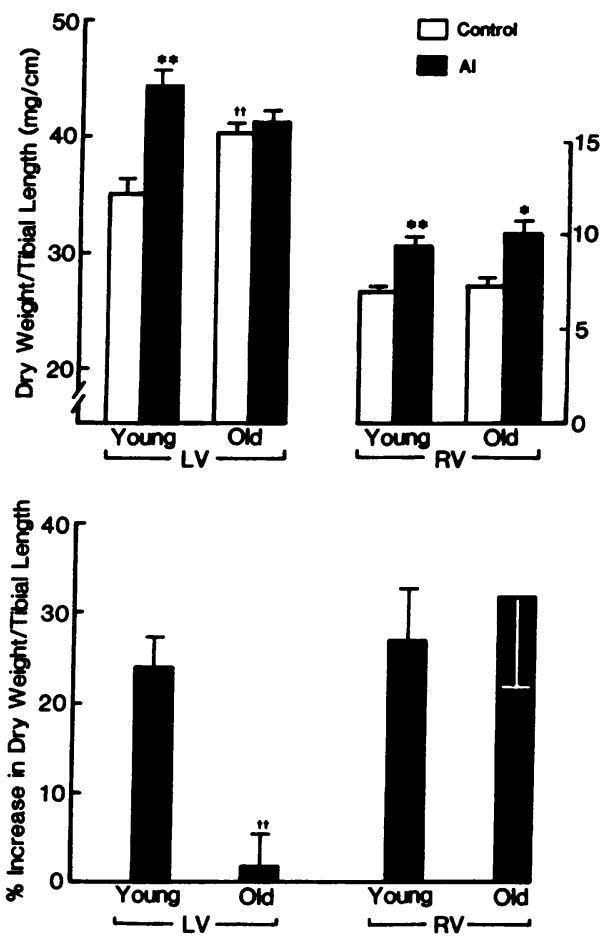

Figure 7. Dry weight/tibial length and percent increase of the ratio in young and old rats at $\mathbf{4} \mathbf{w k}$ after induction of AI. Values are mean \pm SE. Symbols are the same as in Figs. 2 and 3.

in the ratio. Therefore, in the initial period of AI, similar $\mathrm{LV}$ systolic pressure and elevation of end-diastolic pressure should produce similar levels of systolic and end-diastolic wall stress in the young adult and old rats (Eq. 5 in Methods).

In young adult rats, $\mathrm{LV}$ end-diastolic pressure decreased significantly toward normal by 2 wk after induction of $\mathrm{AI}$, and did not show a further reduction thereafter (Fig. 3). At 4 wk the LV end-diastolic pressure and end-diastolic wall stress were still significantly higher than in the age-matched control rats (Figs. 3 and 5). The acute phase of the adaptation process to volume overload seemed to be accomplished by 2 wk after the stimulus in the young adult rats, judging from the changes in LV end-diastolic pressure. This time course of adaptive changes appears to be slightly earlier but similar to the changes in LV end-diastolic pressure or end-diastolic pressure-dimension relationship observed in canine hearts with volume overload in the reports of Lee et al. (28), Badke and Covell (29),

Table III. Protein Concentration and Total Content in LV Myocardium at 4 wk after Induction of $A I$

\begin{tabular}{|c|c|c|c|c|}
\hline & \multicolumn{2}{|c|}{ Young rats } & \multicolumn{2}{|c|}{ Old rats } \\
\hline & Control $(n=9)$ & $\mathrm{AI}(n=8)$ & Control $(n=6)$ & $\mathrm{AI}(n=7)$ \\
\hline $\begin{array}{l}\text { Concentration } \\
\quad(m g / g \text { wet } w t)\end{array}$ & $128 \pm 7$ & $128 \pm 5$ & $127 \pm 9$ & $132 \pm 4$ \\
\hline Total content $(m g)$ & $\begin{array}{l}91 \pm 6 \\
L_{P}<0 .\end{array}$ & 121 & $\stackrel{106 \pm 7}{\llcorner}$ NS & $119 \pm 3$ \\
\hline
\end{tabular}

Values are mean \pm SE. 
and McCullagh et al. (30). These findings are consistent with the hypothesis that volume overload hypertrophy develops in response to increased end-diastolic wall stress, and that the hypertrophic process proceeds in such a way as to return ventricular diastolic pressure and wall stress toward normal: presumably this is accomplished by increasing chamber capacity through series addition of new sarcomeres, thereby accommodating the volume overload $(2,4,5)$.

In contradistinction to the young adult rats, the old rats with $\mathrm{AI}$ did not show a reduction in $\mathrm{LV}$ end-diastolic pressure over time. Instead, they demonstrated elevation of the LV end-diastolic pressure at 2 and 4 wk after AI at levels that were even higher than those measured immediately after AI (Fig. 3). The old rats with AI showed high mortality in the later phase ( 1 wk after AI) of the experiment compared with almost none for the young adult rats with AI. It seems unlikely that the LV end-diastolic pressure or wall stress might decrease after the 4-wk period as a result of late LV hypertrophy in old rats.

The significant LV and RV hypertrophy in the young adult rats with AI (Fig. 7 and Table III) correlated with lower LV diastolic pressure or wall stress (Figs. 3 and 5), and normal water content in the lung and liver. Furthermore, as reported by Grimm et al. (31), Geha et al. (32), and Pannier (33), systolic performance, estimated by isovolumic systolic force generating ability, was normal compared with the age-matched controls, when the ability was assessed by wall stress to normalize for the changes in the chamber size and wall thickness (34) (Fig. 5). In contrast, old rats showed less hypertrophy (Fig. 7), persistently higher LV end-diastolic pressure or stress (Figs. 3 and 5), and higher water content in the lung. Although in the control rats the age-related changes in pressure or stress-generating ability were minimal, as in the reports of Lakatta and Yin (14) and Capasso et al. (35), in the old rats with AI the isovolumic force generating ability was significantly lower compared with the young adult rats with AI (Fig. 6). These findings underscore the vulnerability of the older cardiovascular system to volume overload stimuli that would be well tolerated by younger systems (1).

Of interest, significant RV hypertrophic response was observed in both the young adult and old rats after 4 wk of $\mathrm{AI}$ (Fig. 7). Although we did not directly measure hemodynamic changes in the right heart, one of the factors contributing to the development of RV hypertrophy would be a high pulmonary artery pressure caused by high LV end-diastolic pressure and left atrial pressure. Several different findings in the process of aging between the LV and RV have been reported. In the LV, total muscle mass as well as individual myocyte size increase, and there is a reduction in the number of myocytes with aging from 10 to 20 mo of age $(8,9,12-15,17,18,36)$. On the other hand, the increase in total muscle mass in the RV is relatively less compared with the $\operatorname{LV}(9,13)$. Therefore, the different preexisting condition between the $L V$ and $R V$ in aged rats might modify the further extent of hypertrophy in response to volume overload. Furthermore, Flaim et al. (37) and Anversa et al. (38) have reported that the hypertrophic response of the $\mathrm{RV}$ was greater than for the $\mathrm{LV}$ in an experimental rat model of arteriovenous shunt (37) or running exercise (38). From our present study, it is not clear whether the different hypertrophic response between the $L V$ and $R V$ in the old rats might be caused by the differently existing structural conditions or other different characteristics between the LV and RV.

In our previous study (9), the effect of age on cardiac hy- pertrophy in response to pressure overload at the organ level estimated by ventricular muscle weights was similar to that at the cell level estimated by myocyte width. In addition, there was no significant difference in the degree of fibrosis between rats with and without pressure overload, even in rats of advanced age. Therefore, in this study we estimated the degree of hypertrophy by ventricular muscle weights and protein content. The decreased LV hypertrophic response in old rats is compatible with the results in a pressure overload experimental model previously reported by our laboratory (9). McCafferty and Edington (8) have reported that in animal models of exercise, the cardiac hypertrophic response in the senescent was less compared with the young adult animals. On the other hand, Florini et al. (6) and Zitnik and Roth (7) have reported that hormonal stimulation (thyroid hormone) caused a similar extent of hypertrophy in old rats and old mice compared with young adult animals $(6,7)$. Therefore, the effect of age on hypertrophy may depend upon the type of stimulus, i.e., hormonal or hemodynamic stimulation. In old animals, ribosomal RNA content in the myocardium after pressure overload was found to be significantly lower in our previous study (9) and in the reports of Johnson et al. (39) and Meerson et al. (40), indicating that the capacity for protein synthesis in response to pressure overload may be decreased in old humans and animals. The subcellular process for protein synthesis and degradation may be different between hemodynamic overload and hormonal stimulation. Even in a model of hemodynamic overload, hormonal factors modulate hypertrophic response in the process of molecular stimulation, linking increased circulatory demand to myocardial hypertrophy and/or the process of protein synthesis and degradation within myocardial cells (41-44). From our present study it is not clear how differently these factors may modify the hypertrophic response in young adult and old animals under hemodynamic overload.

In summary, our study demonstrates that advanced age is associated with a diminished capacity for LV hypertrophy in response to a volume overload stimulus. This reduced LV hypertrophic response in the old rats resulted in persistent elevation of LV end-diastolic pressure and wall stress. These findings in our present study may help to explain the clinical observation that heart failure occurs more frequently in old patients compared with younger individuals in response to a similar stress (1).

\section{Acknowledgments}

This study was supported in part by grants from National Institutes of Health (HL-37871 and AG-06443) and the Veterans Administration, and by a Research Fellowship (to Dr. Isoyama) from the American Heart Association, Massachusetts Affiliate.

\section{References}

1. Wei, J. Y., and B. J. Gersh. 1987. Heart disease in the elderly. Curr. Probl. Cardiol. 12:1-65.

2. Grossman, W., D. Jones, and L. P. McLaurin. 1975. Wall stress and patterns of hypertrophy in the human left ventricle. J. Clin. Invest. 56:56-64.

3. Zak, R. 1984. Overview of the growth process. In Growth of the Heart in Health and Disease. R. Zak, editor. Raven Press, New York. $1-24$.

4. Grossman, W., B. A. Carabello, S. Gunther, and M. A. Fifer. 1983. Ventricular wall stress and the development of cardiac hypertrophy and failure. In Perspectives in Cardiovascular Research. Vol 7. N. R. Alpert, editor. Raven Press, New York. 1-18. 
5. Grossman, W. 1980. Cardiac hypertrophy: useful adaptation or pathologic process? Am. J. Med. 69:576-584.

6. Florini, J. R., Y. Saito, and E. J. Manowitz. 1973. Effect of age on thyroxine-induced cardiac hypertrophy in mice. J. Gerontol. 28:293-297.

7. Zitnik, G., and G. S. Roth. 1981. Effects of thyroid hormones on cardiac hypertrophy and beta-adrenergic receptors during aging. Mech. Ageing Dev. 15:19-28.

8. McCafferty, W. B., and D. W. Edington. 1974. Skeletal muscle and organ weights of aged and trained male rats. Gerontologia. 20:4450.

9. Isoyama, S., J. Y. Wei, S. Izumo, P. Fort, F. J. Schoen, and W. Grossman. 1987. The effect of age on the development of cardiac hypertrophy produced by aortic constriction in the rat. Circ. Res. 61:337-345.

10. Lin, H. L., K. V. Katele, and A. F. Grimm. 1977. Functional morphology of the pressure- and the volume-hypertrophied rat heart. Circ. Res. 41:830-836.

11. Schoen, F. J., G. M. Lawrie, and J. L. Titus. 1984. Left ventricular cellular hypertrophy in pressure- and volume-overload valvular heart disease. Hum. Pathol. 15:860-865.

12. Lakatta, E. G. 1979. Alterations in the cardiovascular system that occur in advanced age. Fed. Proc. 38:163-167.

13. Yin, F. C. P., H. A. Spurgeon, M. L. Weisfeldt, and E. G. Lakatta. 1980. Mechanical properties of myocardium from hypertrophied rat hearts. A comparison between hypertrophy induced by senescence and by aortic banding. Circ. Res. 46:292-300.

14. Lakatta, E. G., and F. C. P. Yin. 1982. Myocardial aging: functional alterations and related cellular mechanisms. Am. J. Physiol. 242:H927-H941.

15. Yin, F. C. P., H. A. Spurgeon, K. Rakusan, M. L. Weisfeldt, and E. G. Lakatta. 1982. Use of tibial length to quantify cardiac hypertrophy: application in the aging rat. Am. J. Physiol. 243:H941H947.

16. Wei, J. Y., H. A., Spurgeon, and E. G. Lakatta. 1984. Excitation-contraction in rat myocardium: alterations with adult aging. $\mathrm{Am}$. J. Physiol. 246:H784-H791.

17. Li, Y. X., D. Mendelowitz, T. Lincoln, W. Grossman, and J. Y. Wei. 1986. Age-related differences in the effect of exercise training on cardiac muscle function in the rat. Am. J. Physiol. 251:H12-H18.

18. Wei, J. Y., D. Mendelowitz, N. Anastasi, and J. W. Rowe. 1986. Maintenance of carotid baroreflex function in advanced age in the rat. Am. J. Physiol. 250:R1047-R1051.

19. Jouannot, P., B. Gourdier, and P. Y. Hatt. 1973. L'hypertrophie cardiaque experimentale du rat. Etude comparative de divers types de surcharge mecanique. Arch. Mal. Coeur. 8:1067-1076.

20. Apstein, C., Y. Lecarpentier, J. J. Mercadier, J. L. Martin, C. Wisnewsky, B. Swynghedauw, and K. Schwartz. 1982. Changes in contractility and myosin after aortic insufficiency: heart failure or physiologic adaptation? Circulation. 66(Suppl. II):II-132. (Abstr.)

21. Pfeffer, M. A., J. M. Pfeffer, M. C. Fishbein, P. J. Fletcher, J. Spadaro, R. A. Kloner, and E. Braunwald. 1979. Myocardial infarct size and ventricular function in rats. Circ. Res. 44:503-512.

22. Maruyama, Y., K. Ashikawa, S. Isoyama, H. Kanatsuka, E. Ino-oka, and T. Takishima. 1983. Mechanical interaction between four heart chambers with and without pericardium in canine hearts. Circ. Res. 50:86-100.

23. Fletcher, P. J., J. M. Pfeffer, M. A. Pfeffer, and E. Braunwald. 1981. Left ventricular diastolic pressure-volume relations in rats with healed myocardial infarction. Effects on systolic function. Circ. Res. 49:618-626.
24. Grossman, W. 1986. Pressure measurement. In Cardiac Catheterization and Angiography. 3rd ed. W. Grossman, editor. Lea and Febiger, Philadelphia. 118-134.

25. Lowry, O. H., N. J. Rosebrough, A. L. Farr, and R. J. Randall. 1951. Protein measurement with Folin phenol reagent. J. Biol. Chem. 193:265-275.

26. Mendez, J., and A. Keys. 1960. Density and composition of mammalian muscle. Metab. Clin. Exp. 9:184-188.

27. Mirsky, I. 1979. Elastic properties of the myocardium: a quantitative approach with physiological and clinical applications. In Handbook of Physiology. Vol. 1. R. M. Berne and N. Sperelakis, editors. American Physiological Society, Bethesda, MD. 497-531.

28. Lee, J. D., S. Sasayama, Y. Kihara, A. Ohyagi, A. Fugisawa, Y. Yui, and C. Kawai. 1985. Adaptations of the left ventricle to chronic volume overload induced by mitral regurgitation in conscious dogs. Heart Vessels. 1:9-15.

29. Badke, F. R., and J. W. Covell. 1979. Early changes in left ventricular regional dimensions and function during chronic volume overloading in the conscious dog. Circ. Res. 45:420-428.

30. McCullagh, W. H., J. W. Covell, and J. Ross, Jr. 1972. Left ventricular dilatation and diastolic compliance changes during chronic volume overloading. Circulation. 45:943-951.

31. Grimm, A. F., R. Kubota, and W. V. Whitehorn. 1963. Properties of myocardium in cardiomegaly. Circ. Res. 12:118-124.

32. Geha, A. S., J. P. Duffy, and H. J. C. Swan. 1966. Relation of increase in muscle mass to performance of hypertrophied right ventricle in the dog. Circ. Res. 19:255-259.

33. Pannier, J. L. 1971. Contractile state of papillary muscles obtained from cats with moderate right ventricular hypertrophy. Arch. Int. Physiol. Biochem. 79:743-752.

34. Ross, J., Jr, and W. H. McCullagh. 1972. Nature of enhanced performance of the dilated left ventricle in the dog during chronic volume overloading. Circ. Res. 25:549-556.

35. Capasso, J. M., A. Malhotra, R. M. Remily, J. Scheuer, and E. H. Sonnenblick. 1983. Effects of age on mechanical and electrical performance of rat myocardium. Am. J. Physiol. 245:H72-H81.

36. Anversa, P., B. Hiler, R. Ricci, G. Guideri, and G. Olivetti. 1986. Myocyte cell loss and myocyte hypertrophy in the aging rat heart. J. Am. Coll. Cardiol. 8:1441-1448.

37. Flaim, S. F., W. J. Minteer, S. H. Nellis, and D. P. Clark. 1979. Chronic arteriovenous shunt: evaluation of a model for heart failure in rat. Am. J. Physiol. 236:H698-H704.

38. Anversa, P., C. Beghi, V. Levicky, S. L. McDonald, and Y. Kikkawa. 1982. Morphometry of right ventricular hypertrophy induced by strenuous exercise in rat. Am. J. Physiol. 243:H856-H861.

39. Johnson, L. K., R. W. Johnson, and B. L. Strehler. 1975. Cardiac hypertrophy, aging and changes in cardiac ribosomal RNA gene dosage in man. J. Mol. Cell. Cardiol. 7:125-133.

40. Meerson, F. Z., M. P. Javich, and M. I. Lerman. 1978. Decrease in the rate of RNA and protein synthesis and degradation in the myocarium under long-term compensatory hyperfunction and aging. $J$. Mol. Cell. Cardiol. 10:145-159.

41. Lipana, J. G., and B. L. Fanburg. 1970. Heart growth in response to aortic constriction in the hypophysectomized rat. Am. J. Physiol. 218:641-646.

42. Cohen, J. 1974. Role of endocrine factors in the pathogenesis of cardiac hypertrophy. Circ. Res. 35(Suppl. II):II-49-II-57.

43. Oparil, S., S. P. Bishop, and F. J. Clubb, Jr. 1984. Myocardial cell hypertrophy or hyperplasia. Hypertension. 6(Suppl. III):III-38-III43.

44. Oparil, S. 1985. Pathogenesis of ventricular hypertrophy. Am. J. Coll. Cardiol. 5:57B-65B. 